\title{
New editors appointed
}

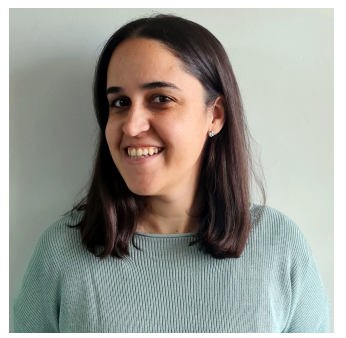

Jezabel Curbelo is Ramon y Cajal researcher in the Department of Mathematics at Universitat Politècnica de Catalunya, Spain, since July 2020 and member of the Institute of Mathematics (IMTech) of UPCBarcelonaTech. She obtained her PhD in mathematics (2014) at Universidad Autónoma de Madrid. Her thesis was awarded in the field of nonlinear geophysics with the 2015 Donald L. Turcotte Award (American Geophysical Union). After that, she was a postdoc LabEX LIO at Laboratoire de Géologie de Lyon (CNRS/ENS Lyon/Lyon1) (2014-2016), Juan de la Cierva Formación Postdoc at Universidad Politécnica de Madrid (Apr-Sep 2016), Assistant Professor at Universidad Autónoma de Madrid (Sep 2016 - Jan 2020) and Visiting Assistant Researcher at University of California Los Angeles (Feb - Jun 2020).

She has been awarded with the "2020/2021 L'Oréal-UNESCO For Women in Science" award, edition "Spain - National Young Talents Programme 2020" and the "2020 Antonio Valle SEMA Prize for Young Researchers".

Her research focuses mainly on applied mathematics in geophysical fluids and related problems. More specifically in the simulation and modeling of nonlinear processes underlying fluid motion and in the description of transport, mixing and stirring in the ocean and atmosphere from the standpoint of dynamical systems theory. She also investigates fundamental behaviours of fluid processes in planetary mantles, where she analyses convective motions. Her webpage is web.mat.upc.edu/jezabel.curbelo/

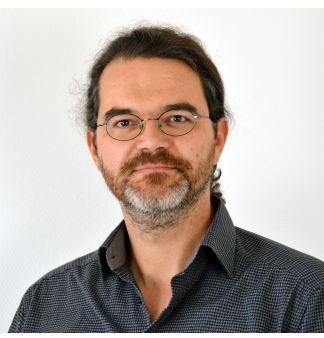

Photo by Friederike von Heyden/Bergische Universität Wuppertal
Ralf Krömer studied mathematics and computer science in Saarbrücken (Germany). His PhD thesis concerned the history and philosophy of category theory and was written in a French-German cotutelle between Saarbrücken and Nancy. Postdoc positions included work at Aix-enProvence, Hannover (Leibniz edition) and Nancy (Poincaré edition). After a time as a teacher of mathematics and music in secondary school in Germany, he was a lecturer in mathematics at Siegen University; since 2013, he is professor for mathematics and its didactics at Wuppertal University.

Ralf Krömer's research is mainly in the history of mathematics from the late 17th to the 20th century. Research interests include, in particular, historical themes around Leibniz, Poincaré, the Bourbaki group, structural mathematics, and category theory, but also philosophical aspects of these topics as well as the use of the history of mathematics in its teaching. He is currently working on a large collective publication on duality in 19th and 20th century mathematical thinking. His webpage is www2.math.uni-wuppertal.de/ -kroemer/ 